\title{
One Dimensional Steady State Model for Studying Hydration of Membrane in Proton Exchange Membrane Fuel Cell
}

\author{
Narender Kumar, Purnima Swarup Khare
}

\begin{abstract}
A one dimensional model steady state model of Proton Exchange Membrane Fuel Cell to study the hydration of electrolyte membrane, diffusion of the water on the membrane and water transport in the membrane (electro osmotic drag and back diffusion) is presented. Initially the theoretical formulation of the process inside the PEMFC is done based on the electro chemical equation and reactions. The simulation of the theoretical electrochemical model presented in this study has been done on the MATLAB computational model. Results were compared with the experimental data to investigate the convergence between them and to validate the model in order of establishing confidence in the model when used with rather small FC stacks. The conclusions coming out of this study show that the simulation results are in good agreement with the experimental data and consequently this model can be reliably used.
\end{abstract}

Index Terms-Back diffusion, electro osmotic drag, water transport coefficient, proton exchange membrane fuel cell.

\section{INTRODUCTION}

It is well known that proper water management inside a polymer electrolyte membrane (PEM) fuel cell is essential for obtaining high performance. Insufficient water lowers the conductivity of the membrane and yields low currents at a fixed voltage whereas excess water leads to flooding of the electrode and low currents at a fixed voltage due to a decreased reaction area. Typically the internal hydration is adjusted by the inlet humidity of the feed streams however the optimum depends on the given membrane

and electrode assembly. As Scherer et al [1] discusses, the properties of the diffusion layer will impact the optimum performance of the catalyst and the electrode. These diffusion layers can be porous carbon cloths coated with PTFE as presented by Bevers et al. [2]. Water transport in a fuel cell membrane occurs by electro-osmotic drag from the anode to cathode (as current is drawn) and by back diffusion from the cathode to anode (as water is produced) because of the difference in water concentration between the electrodes. However, the inlet gases are also usually humidified to ensure operating conditions where the PEM will have high ionic conductivity values. For example, standard PEMs such

Manuscript received June 2, 2011; revised July 15, 2011.

Narender Kumar is Research Associate Physics Department, Rajiv Gandhi Technological University Bhopal (M.P) India - 462026.

Purnima Swarup Khare is Professor \& Head of Physics Department Rajiv Gandhi Technological University Bhopal (M.P) India- 462026

Corresponding author (Email: drnarender78@gmail.com , Mobile No $+91-9993419428)$ as Nafion ${ }^{\circledR}$ require fuel cell operating conditions of least $80 \%$ $\mathrm{RH}$ for acceptable performance T.A. Zawodzinski et al [3] and Q.G. Yan et a [4]. Hammond and Farhat [5] has shown that PEMs constructed by the layer by- layer (LBL) assembly technique can perform comparably or even better than Nafion ${ }^{\circledR}$ systems at lower humidities $(<60 \% \mathrm{RH})$. Springer et al [6] has been studied the conductivity of proton in the membrane, which is dependent on the water content (i.e. moles of water per mole of sulfonic acid sites). When the membrane is saturated, the hydraulic model provides a better approximation of the water transport as discussed by $\mathrm{M}$. Eikerling et al.[7] and J. Fimrite et al.[8] . Fuqiang Liu [9] has studied the water transport coefficient in proton exchange membrane fuel cell. It is found that the local current density is dominated by the membrane hydration and that the gas $\mathrm{RH}$ has a large effect on water transport through the membrane.

In this study the performance proton exchange membrane fuel cell is linked to the hydration of the electrolyte membrane, an iterative procedure to compute the coupled diffusion equations of the reactants and the water transport in the membrane can be considered. That way, the membrane resistance behaviour can be predicted for various relative humidity of the inlet gas. The water transport is always a balance between at least two competing diffusion mechanisms. One is due to the proton displacement from anode to cathode that drags some water molecules with them (called electro-osmotic drag). The other mechanism is back diffusion of water from cathode to anode. This water flux results from the water concentration gradient created in the membrane by the electro osmotic drag and the water produced by the redox reaction at the cathode.

The model presented in this section is a one-dimensional steady-state single-cell model with two differential equation systems coupled at the anode and the cathode. The model regions consist of a membrane sandwiched between two gas diffusion layers.

\section{Operating Principle of Proton Exchange MEMBRANE FUEL CELL}

Fig. 1 shows the schematic diagram of proton exchange membrane fuel cell. There is an electrolyte membrane in the center. Anode and cathode are located in the membrane's both sides, which is called as Membrane Electrolyte Assembly (MEA). Nafion is generally used for MEA. It allows the only hydrogen ions $(\mathrm{H}+)$ to pass through it. The electrode, catalyst and carbon are mixed for maximizing the response areas. The gas diffusion layer (GDL) for similarly supporting the fuel exists in the electrode's both sides. 
The bipolar plate plays a role in the channel supporting reactant, water removal, an electron collector. The reactant moves in the channel of the bipolar plate and removed. The channel plays an important role the fuel cell performance. Fig. 2 shows the operating principle of the PEMFC. The humid fuel is supported to the channel of the bipolar plate through manifold

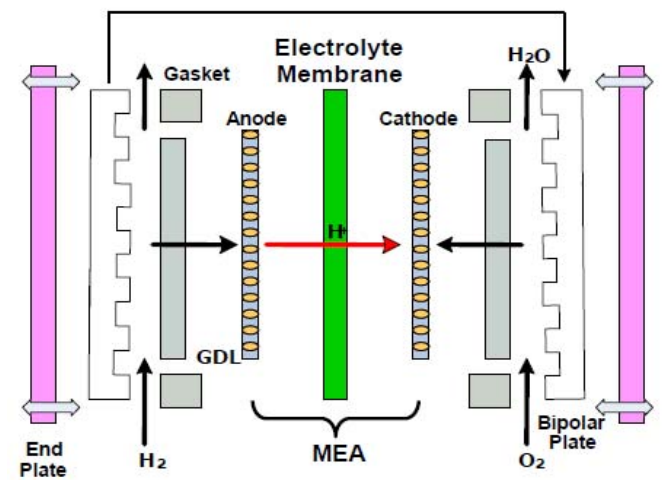

Fig. 1.Schematic Diagram of PEMFC

One must humidify the fuel because the ion conductivity is high when hydrogen ion is $\mathrm{H}_{3} \mathrm{O}^{+}$Diks and Larminie, [10]. The reaction at the anode is oxidation. The MEA separates two gases which is the hydrogen ion and electron. The hydrogen ions move through the membrane to the cathode. The electrons travel the bipolar plate and go out the external circuit creating useful current. The reaction at the cathode is deoxidation. The hydrogen ions combine with oxygen to produce water and heat energy.

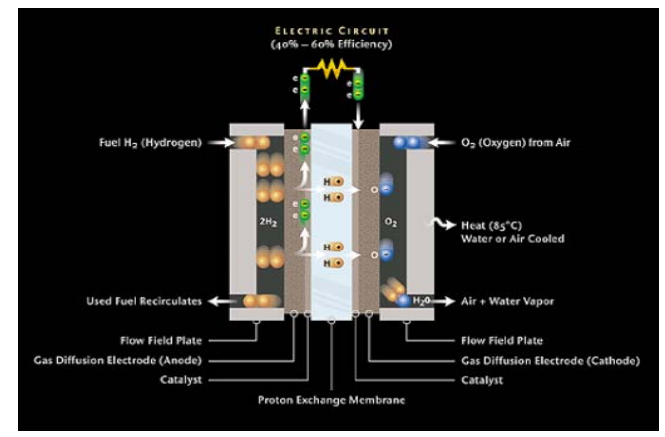

Fig. 2.Operating Principle of PEMFC

The electrochemical reactions which takes place at anode and cathode;

$$
\begin{array}{ll}
\text { At Anode: } & \mathrm{H}_{2} \rightarrow 2 \mathrm{H}^{+}+2 e^{-} \\
\text {At Cathode: } & \frac{1}{2} \mathrm{O}_{2}+2 \mathrm{H}^{+}+2 e \rightarrow \mathrm{H}_{2} \mathrm{O} \\
\text { Over all reaction: } & \mathrm{H}_{2}+\frac{1}{2} \mathrm{O}_{2} \rightarrow \mathrm{H}_{2} \mathrm{O}
\end{array}
$$

\section{MATHEMATICAL EQUATIONS}

The molar flow rates of hydrogen $N_{\mathrm{H}_{2}}(y)$ and water $N_{\mathrm{H}_{2} \mathrm{O}}(y)$ along the anode channel length y varies because of the hydrogen oxidation reaction and net water transport through the polymer membrane. The molar flow rates of hydrogen $N_{\mathrm{H}_{2}}(y)$ and water $N_{\mathrm{H}_{2} \mathrm{O}}(y)$ can be calculated as [9];

$$
\frac{d N_{H_{2}}(y)}{d y}=-r \frac{i(y)}{2 F}
$$

$$
\frac{d N_{H_{2 O}}(y)}{d y}=-r \frac{\alpha(y) * i(y)}{F}
$$

The current density i (y) and net water transport coefficient $\alpha$ (y) vary along the channel length with the membrane conductivity and water uptake. After solving the equations (4) and (5) the water transport coefficient $\alpha(y)$ is given as [9]

$$
\alpha(y)=-\frac{F}{r * i(y)} \frac{d}{d y}\left\{\left(N_{H_{2}}^{i n}-\frac{r}{2 F} \int_{0}^{y} i(y) d y\right) \frac{x_{H_{2} O}^{a}(y)}{x_{H_{2}}(y)}\right\}
$$

For the detailed solution of equations (4) and (5) the reader my refers the reference [9]

The net water transport coefficient $\alpha(y)$ can be mathematically represented as [9];

$$
\alpha(y)=\eta_{\text {dragg }}-\frac{F}{i(y)} \frac{D_{\lambda} \rho^{d r y}\left(\lambda_{c}-\lambda_{c}\right)}{t_{m}(E W)}
$$

The amount of water that the membrane can hold depends upon the temperatures and the water uptake of the cell. The relationship between the water activity on the faces of the membrane and water content can be described by [11]

$\lambda=0.043+17.2 \mathrm{a}_{\mathrm{H} 2 \mathrm{O}, \mathrm{vap}}-39.9\left(\mathrm{a}_{\mathrm{H} 2 \mathrm{O}, \mathrm{vap}}\right)^{2}+36\left(\mathrm{a}_{\mathrm{H} 2 \mathrm{O}, \mathrm{vap}}\right)^{3}(8)$

The ionic conductivity, water content and temperature are correlated with the following relation [6]

$$
\sigma=\left(51.4 * 10^{-4} \lambda-32.6 * 10^{-4}\right) \times \exp \left[1268\left(\frac{1}{303}-\frac{1}{T}\right)\right]
$$

Therefore the total resistance of the membrane can be calculated as [6]

$$
R_{m}=\int_{0}^{t_{m}} \frac{d z}{\sigma[\lambda(z)]}
$$

The total amount of water in the membrane can be calculated as

$$
J_{\mathrm{H}_{2} \mathrm{O}}=\eta_{\text {dragg }} \times J_{\mathrm{H}_{2} \mathrm{O}, \text { dragg }}-J_{\mathrm{H}_{2} \mathrm{O}, \text { backdiff }}
$$

where, $\eta_{\text {dragg }}$ is the proton in the membrane typically have one or more molecules associated with them. Therefore the number of water molecules that accompanies each proton (electro osmotic drag) is ;

$$
n_{\text {drag }}=n_{\text {drag }}^{\text {sat }} \frac{\lambda}{22}
$$

$J_{H_{2} O \text {,dragg }}$ is the water drag flux from the anode to cathode with net current density is given as [12]

$$
J_{H 2 O, d r a g}=2 n_{\text {drag }} \frac{i}{2 F}
$$

The water back diffusion flux $\left(J_{H_{2} \text { O,backdiff }}\right)$ can be determine by [6] 


$$
J_{H 2 O, \text { backdiff }}=\frac{\rho_{d r y}}{M_{m}} D_{\lambda} \frac{d \lambda}{d z}
$$

where, $D_{\lambda}$ is the water diffusion coefficient in the membrane and can be calculated as [13]

$$
D_{\lambda}=0.035 * \lambda * e^{(-243.6 / T)}
$$

Hence from equation (11) the total amount of water in the membrane can be calculated as

$$
J_{H 2 O}=n_{\text {drag }}^{\text {sat }} \frac{\lambda}{22} \times 2 n_{\text {drag }} \frac{i}{2 F}-\frac{\rho_{\text {dry }}}{M_{m}} D_{\lambda} \frac{d \lambda}{d z}
$$

The total fuel cell losses can be written as

$$
\eta_{\text {ohmic }}=I\left(R_{e}+R_{m}\right)
$$

And the fuel cell output voltage is given by [14]

$$
V_{\text {cell }}=E_{\text {nernst }}-\eta_{\text {ohmic }}-\eta_{\text {con }}-\eta_{\text {act }}
$$

where;

$$
\begin{gathered}
\eta_{a c t}=-b \cdot \log _{10}\left(\frac{i}{i o}\right) \\
b=\frac{R T}{2 \alpha F}
\end{gathered}
$$

where $b$ is also known as Tafel slop.

The detail of the parameters which has been used in the research work is as given in the table1.

\section{RESUlt AND Discussion}

As shown in figure (3) as water transport coefficient increases the membrane thickness also increases. This is because of the increase in the water drag inside the membrane by the proton which cause the swelling in membrane and the thickness of the membrane increases. As seen from the figure (3) at a particular thickness approximately $0.008 \mathrm{~cm}$ the water transport coefficient becomes almost constant.

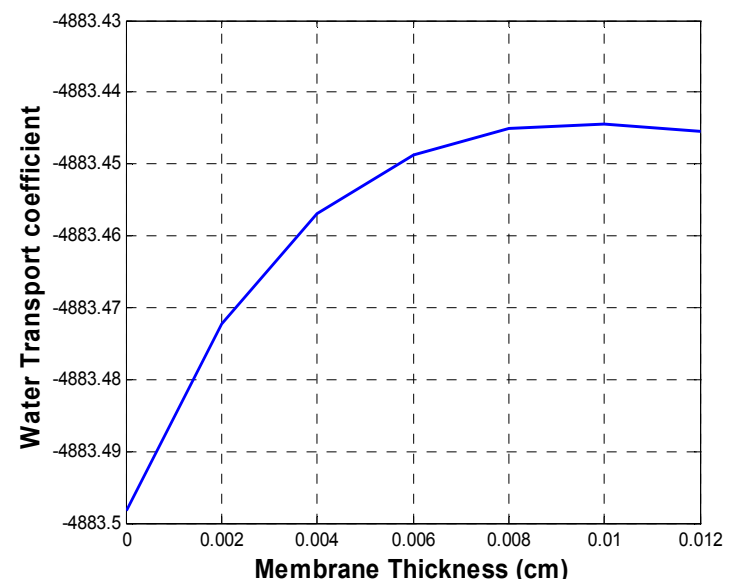

Fig. 3.Water Transport Coefficient Variation with Membrane Thickness
From figure (2), it is seen that water content inside the membrane increases with the thickness. This is because of osmotic drag moves water in fuel cell from anode to cathode. Since the reaction at the cathode produces water, it tends to humidify the cathode, and some water travels back through the membrane.

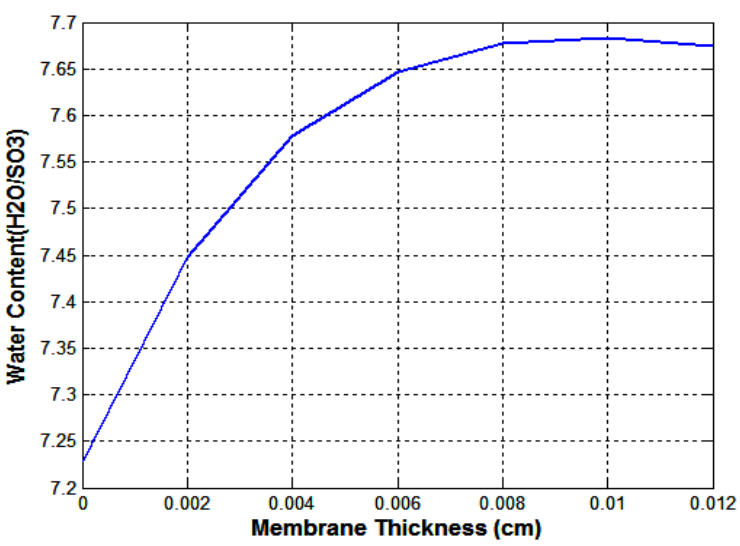

Fig. 4.Water Content Variation with Membrane Thickness

The water uptake results in membrane swelling, which changes the membrane thickness along with its conductivity as shown in figure (3). Therefore local conductivity of the water molecules inside the membrane increases with the thickness. The local conductivity in the membrane is also proportional to its resistance. This will result the increase in the membrane resistance.

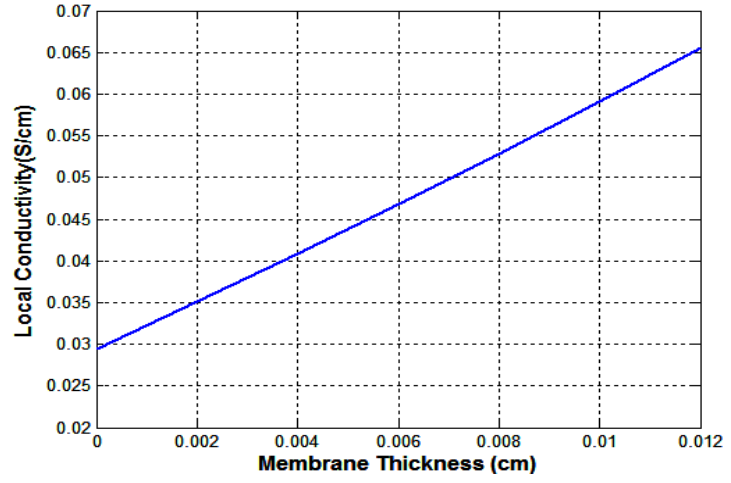

Fig. 5.Local Conductivity Variations with Membrane Thickness

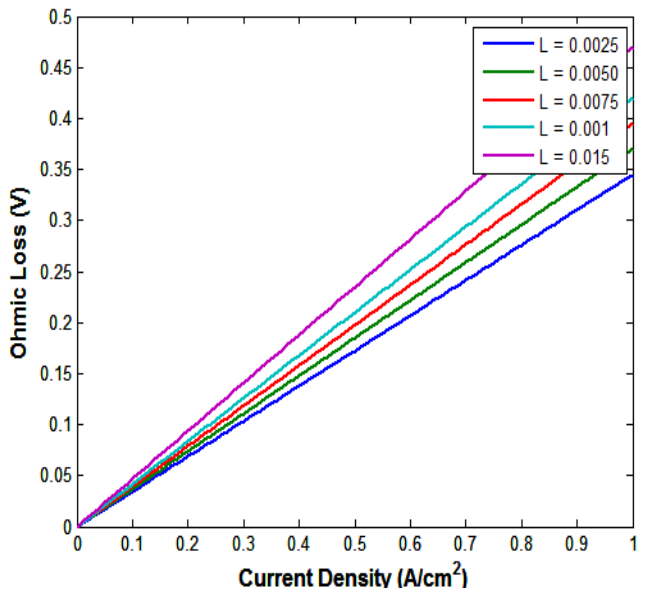

Fig. 6.Ohmic loss Variation with Membrane Thickness

The Ohmic loss in the membrane is also increases with the increase in the membrane thickness as shown in figure (4).This is because of the increases in the local conductivity 
in the membrane.

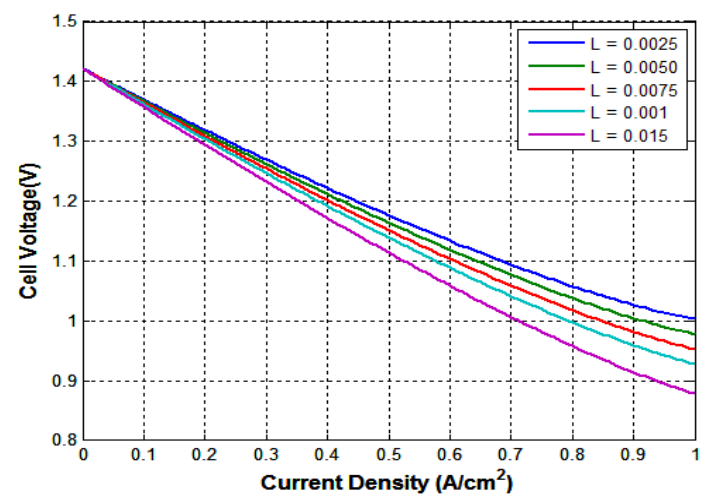

Fig. 7.Cell Voltage vs. Current Density at Different Membrane

The current voltage curve of the typical fuel cell is shown in the figure (5). From figure (6) for a thinner and thicker membranes one will notice that the cell voltage is reduced with thinner membrane because of decrease in ohmic losses.

\section{CONCLUSION}

From this study it is concluded that the largest Ohmic losses occurs during the transport of the ions through the membrane. To decrease the ionic losses through the membrane, either the membrane needs to be more conductive or the membrane needs to become thinner. It is usually easier to make the membrane thinner however developing high conductivity membrane is very challenging. The challenge occurs in creating a material that is not highly conductive also stable in chemical environment at high temperature.

TABLE I: NOMENCLATURE AND PARAMETERS VALUES

\begin{tabular}{|c|c|c|}
\hline Symbol & Meaning & Value \\
\hline$a_{H 2 O, v a p}$ & Water vapor activity & 0.8 \\
\hline $\mathrm{A}$ & Area of the membrane $\left(\mathrm{cm}^{2}\right)$ & 64 \\
\hline$E_{\text {nernst }}$ & Nernst voltage $(\mathrm{V})$ & 1.229 \\
\hline $\mathrm{F}$ & Faraday Constant & 96487 \\
\hline $\mathrm{EW}$ & Equivalent weight of membrane & \\
\hline$i_{0}$ & Exchange current density $\left(\mathrm{A} / \mathrm{cm}^{2}\right)$ & $10^{-6.912}$ \\
\hline$M_{m}$ & Nafion Equivalent weight $(\mathrm{Kg} / \mathrm{mol})$ & 1 \\
\hline $\mathrm{r}$ & Width of the flow channel & --- \\
\hline$R_{e}$ & Electronic resistance $($ ohms $)$ & 0.005 \\
\hline $\mathrm{R}$ & Ideal gas constant $(\mathrm{J} / \mathrm{mol} \mathrm{K})$ & 8.314 \\
\hline$t_{m}$ & Thickness of membrane $(\mu \mathrm{m})$ & $25-150$ \\
\hline
\end{tabular}

\begin{tabular}{|c|c|c|}
\hline $\mathrm{T}$ & Temperature of the cell $\left({ }^{0} \mathrm{C}\right)$ & $20-80$ \\
\hline$x_{\mathrm{H}_{2} \mathrm{O}}^{a}(y)$ & $\begin{array}{c}\text { Water molar fractions along the anode } \\
\text { channel length }\end{array}$ & ---- \\
\hline$x_{\mathrm{H}_{2}}(y)$ & $\begin{array}{c}\text { Hydrogen molar fractions along the anode } \\
\text { channel length }\end{array}$ & ------ \\
\hline $\mathrm{y}$ & Anode channel length $(\mathrm{mm})$ & $0.1-1$ \\
\hline$n_{\text {drag }}^{\text {sat }}$ & Electro osmotic drag & $(2.5 \pm 0.2)$ \\
\hline$\alpha$ & Transfer coefficient & 0.5 \\
\hline$\rho_{\text {dry }}$ & Dry density of Nafion Membrane $\left(\mathrm{Kg} / \mathrm{m}^{3}\right)$ & 0.00197 \\
\hline s $\sigma$ & Conductivity of the membrane $(\mathrm{ohm} / \mathrm{cm})$ & 0.1 \\
\hline$\eta_{\text {con }}$ & Concentration overvoltage & 0 \\
\hline
\end{tabular}

\section{REFERENCE:}

[1] Scherer, G.G “, Interfacial aspects in the development of polymer electrolyte fuel cells" J. Solid State Ionics, 94 (1997), 249- 257

[2] Bevers, D., Rogers, R., von Bradke, M., "Examination of the influence of PTFE coating on the properties of carbon paper in polymer electrolyte fuel cells", J. Power Sources, 63 (1996), 193-201.

[3] T.A. Zawodzinski, C. Derouin, S. Radzinski, R.J. Sherman, V.T. Smith, T.E. Springer and S. Gottesfeld, ."Water Uptake by and Transport Through Nafion $^{\circledR} 117$ Membranes" J. Electrochem. Soc. 140 (4) (1993), 1041-1047.

[4] Q.G. Yan, H. Toghiani and J.X. Wu, "Investigation of water transport through membrane in a PEM fuel cell by water balance experiments" J. Power Sources 158(4) (2006), 316- 325.

[5] T.R. Farhat and P.T. Hammond,'Organized arrays of nanostructures in freely suspended nanomembranes", J. Advanced Functional Materials 15 (2005), 945-951.

[6] T.E. Springer, T.A. Zawodzinski, and S. Gottesfeld." Polymer electrolyte fuel cell model". J. Electrochemical Society, 138(8) (1991), 2334-2342.

[7] M. Eikerling, Yu. I. Kharkats, A. A. Kornyshev, and Yu. M. Volfkovich,"Phenomenological theory of electro-osmotic effect and water management in polymer electrolyte proton-conducting membranes", J. Electrochemical Society, 145(8) (1998), 2684-2699.

[8] J. Fimrite, H. Struchtrup, and N. Djilali," Transport phenomena in polymer electrolyte membranes. part i: Modeling framework", J. Electrochemical Society, 152(9) (2005), A1804-A1814.

[9] Fuqiang Liu, Guoqiang Lu, Chao-Yang Wang,"Water transport coefficient distribution through the membrane in a polymer electrolyte fuel cell," J. Membrane Science 287 (2007), 126-131.

[10] Larminie , James; Diks , Andrew (2000),"Fuel cell system explained", 2nd edition. JOHN WIELY \& SONS, LTD.

[11] Rowe, A., and X. Li.,"Mathematical modeling of proton exchange membrane fuel cells", J. Power Sources. 102 (2001), 82-96.

[12] Sousa, R., Jr., and E. Gonzalez.," Mathematical modeling of polymer electrolyte fuel cells", J. Power Sources. 147 (2005), 32-45.

[13] A.C. West, T.F. Fuller,'Influence of Rib Spacing in Proton-Exchange Membrane Electrode Assemblies', J. Applied Electrochem., 26(1996), 557-565.

[14] R.F Mann. J.C Amphlett, M.A.I Hooper , H.M Jensen , B.A Peppley P. R Roberg," Development and Application of a generalized steady state electrochemical model for a PEM fuel cell", J. Power Sources 86(1/2) (2000) 173-180. 